Arch. Gerontol. Geriatr. Suppl. 1 (2009) 147-151

0167-4943/\$ - see front matter (C) 2009 Elsevier Ireland Ltd. All rights reserved.

\title{
COSTS OF THE IN-HOME PATIENTS AFFECTED BY DEMENTIA
}

\author{
G. ISAIA, M. BO, G. NOBILI*, G. CAPPA, S. MONDINO, S. PILON, M. MASSAIA
}

Department of Medical and Surgical Disciplines, Section of Geriatrics, University of Turin, Corso Bramante 88, I-10126 Torino, Italy

*Corresponding author:

Tel: +(39-011 633 6734); Fax:+(39-0116961045); Email: nobili.giulia@gmail.com

\section{ABSTRACT}

In 2000, Alzheimer's disease (AD) and other dementias were the third most expensive health conditions in the USA and in 2005 their annual costs amounted to more than $\$ 148$ billion. An observational, non-randomized study aimed to evaluate direct costs of demented patients in their homes. Two hundred thirty-six informal caregivers have been enrolled. A financial support, represented by a disability living allowance (15.3\%) or attendance allowance $(3.4 \%)$, was presented in just $19.7 \%$ of the cases. Patients receiving assistance from an employed carer were $39 \%$ with a mean cost of $800 € /$ month. Receiving assistance from an employed carer is not correlated with cognitive and functional impairment, with the age of the caregiver and with the duration of the disease $(t=1.03 ; t=-0.86 ; t=1.41 ; t=$ -0.16 , respectively). The informal caregivers declared that they thoughts about the possibility of institutionalize the patient were $20.9 \%$. The present study underlines the discrepancy between subjects having assistance from an employed caregiver and subjects receiving financial supports. It often happens that patients not reaching the minimum requisites for social assistant or financial support, need at least a supervision.

Keywords: Alzheimer's disease, costs of dementia carings, informal caregivers, employed carers

\section{INTRODUCTION}

Dementia is a clinical syndrome characterized by a cluster of symptoms and signs manifested by difficulties in memory, disturbances in language, psychological and psychiatric changes, and impairment in activities of daily living (Burns and lliffe, 2009). The most common cause of dementia is $A D$ affecting about $6 \%$ of population aged over 65 . About 12 million people worldwide have dementia, and this is likely to increase to 25 million by 2040 (Ferri et al., 2005).

In 2000, AD and other dementias were the third most expensive health condition in the USA, preceded only by hearth disease and cancer, and in 2005 their annual costs amounted to more than $\$ 148$ billion (Alzheimer's Association, 2008). 
In Italy, dementia is the most costly brain disorder. The annual budget needed to support dementia patients amounts to almost €8.6 billion (Pugliatti et al., 2008). Care of demented patients is an extremely onerous task. The deterioration of both cognitive and physical abilities, often associated with non cognitive symptoms, such as psychotic symptoms, depression and change in behavior, results in heavy burden on the caregiver, representing a severe health, economic and social problem. The aim of this study is to estimate the direct costs supported by relatives of demented patients assisted at home.

\section{SUBJECTS AND METHODS}

Two hundred thirty-six informal caregivers attending for cognitive impairment subjects consecutively admitted to the Geriatric outpatients' service for dementia of San Giovanni Battista Hospital of Torino since June to September 2006, have been evaluated for this study. For "informal caregiver" we intend people dedicated to the care of the elderly patient into the family contest (husband/wife, sons/daughters or social assistant). Employed caregivers expressively paid for caring and with no familiar relationships with the patients were not interviewed. Each informal caregiver underwent a specific anonymous questionnaire aimed to collect the following data: presence of employed caregivers in the family and their salary, monthly amount for drugs, diaper's furniture, or money spent for home structural changes necessary for a better ambient living. Moreover, caregivers were asked if they knew and eventually used facilities such as day care centers or disability living allowance

Data on age and gender have been collected too for both the patients and the caregivers. Moreover, the mini mental state examination (MMSE) (Folstein et al., 1975), a brief examination consisting of eleven questions, have been used to evaluate patient's cognitive status. The activity of daily living (ADL) scale (Katz et al., 1963) and the instrumental ADL (IADL) (Lawton and Brody, 1969) have been used to evaluate the functional status of the patients. ADL evaluates the dependency of a subject in carrying out tasks of everyday life, while IADLs are activities related to independent living.

Informed consent for study participation was obtained from the patients or, for those with substantial cognitive impairment, from a proxy by the physician interviewer. Statistical analysis has been performed using SPSS 15.0 packaging for Windows. A descriptive analysis of continuous and categorical variables was performed. We used coefficient of linear correlation $(R)$ for continuous variables. The $x^{2}$-test was used to evaluate the association between categorical variables. The independent-samples t-test procedure was 
used to evaluate differences in mean values between groups (it computes the differences between values of the two variables for each case and tests whether the average differs from 0). The paired-samples t-test procedure was used to evaluate differences between baseline and follow up. All statistical tests were 2-tailed, with $p<0.05$ indicating statistical significance. Data are presented as means \pm S.D., $(95 \%$ confidence intervals $=\mathrm{Cl})$, or as percentages in the corresponding categories.

\section{RESULTS}

Mean age of the sample examined was $79.88 \pm 6.54$ years $( \pm$ S.D.) (range: $58-95$ years). The $28.4 \%$ were males and $71.6 \%$ were females. Patients were cognitively impaired since a mean time of $31.65 \pm 19.43$ months. Mean MMSE score, corrected for age and education, was $15.63 \pm 5.50$ (range: $5-24$ ). Most of the patients $(92.4 \%$ ) were functionally impaired with at least one function lost. Mean IADL score was $4.57 \pm 2.2$.

Caregivers were mainly relatives, with a mean age of $60.27 \pm 13.39$ years: son/daughter $(72.0 \%)$, wife/husband $(23.5 \%)$ and sister/brother or a social worker $(4.5 \%)$. Almost half of the caregivers (45.0\%) was still in working age and more than $50.0 \%$ lived far from the patient's home; $20.0 \%$ of them referred personal health problems forbidding good patient's caring.

A financial support, represented by a disability living allowance $(15.3 \%)$ or attendance allowance $(3.4 \%)$, was presented in just $19.7 \%$ of the cases. Patients receiving assistance from an employed carer were $39.0 \%$ with a mean cost of $€ 800 /$ month (range: $€ 250-1250$ ) for 12 hours/day $(11.86 \pm 9.1)$. In $19.4 \%$ of the cases, a house worker was necessary with a mean cost of $€ 280 /$ month. In $6.4 \%$ of the cases it was necessary to make some structural modification in the patient's residence with a cost that, in $80 \%$ of the cases, was more than $€ 3000$. Moreover, the average monthly expense for drugs and aids was about $€ 100$. There was no correlation between the presence of the carer and the presence of a disability living allowance $\left(X^{2}=0.118, n s\right)$ or an attendance allowance $\left(X^{2}=2.58 ; n s\right)$. Receiving assistance from an employed carer is not correlated significantly with cognitive and functional impairment, with the age of the caregiver and with the duration of the disease $(t=1.03, t=-$ $0.86, t=1.41, t=-0.16$, respectively). Only $6.8 \%$ of the informal caregivers knew and used day care centers and respites.

The informal caregivers declared that they thoughts about the possibility of institutionalize the patient were $20.9 \%$. This decision was independent from the presence of the carer $\left(x^{2}=0.26, n s\right)$, the age of caregiver $(t=-0.65 ; n s)$, the disease span $(t=0.68, n s)$ 
and it was associated to the difficulty of care management caused by the cognitive $(t=-$ $3.88, p=0.001)$ and functional $(t=3.26, p=0.02)$ impairment degree, independently from the presence of a carer.

\section{DISCUSSION}

Management of elderly demented patients represent a cost for the Social Health System, but it is a heavy burden especially for the families. This illness has physical and social effects, such as a poorer health status of caregivers (Shaw et al., 2003) or the abandon of leisure activities and social life (Ory et al., 1999). Moreover, it use seems to be growing to follow and treat at home demented patients. The present study analyzes the financial burden sustained by the relatives of patients affected by dementia.

This study confirms that in Italy, as in many other countries (Alzheimer's New Zealand, 2003), patients with $A D$ or other form of dementia are cared at home and most of the costs are provided by the relatives.

Our results show that only a few portion of patients affected by dementia and functional impairment receive public financial supports. Martin et al. (2008) reported that patients with mild $A D$ show declines in overall financial capacity at 1-year follow up as compared to a healthy older control group. In this study, the capacity compromise increased from $87-91 \%$ with only $9 \%$ of patients with mild AD classified as capable at follow up.

Our results concord with Brunton et al. (2008) showing that even when eligible for respite care services, respondents are often unable to access them. This is due to the difficulty of finding rest homes equipped for the needs of $A D$ patients. This is in contrast with the need of institutionalization showed by a high number of respondents.

Results of the present study underline the high discrepancy between subjects having assistance from an employed caregiver and subjects receiving financial supports. It often happens that patients not reaching the minimum requisites for social assistant or financial support, need at least a supervision. It could depend by behavioral disturbances (Nguyen et al., 2008) or simply by the needs of protect the social and the working life of the relatives (Dang et al., 2008).

This study presents some limits: (1) Patients were non-randomly selected from a University AD center. (2) Data on patients' healthcare costs were reported by informants, that used to be the patient's relatives. Even if there is no reason to think that caregivers' reports are incorrect, may be there are additional costs beyond those collected in the study. (3) The study estimated costs associated with caring for $A D$ patients during the evaluation 
and are not incremental costs due to AD. (4) The study analyzed only the direct costs of demented patient's

CONFLICT OF INTEREST STATEMENT: None.

REFERENCES

Alzheimer's Association (2008): 2008 Alzheimer's disease facts and figures. Alzheimer Dementia 4, 110-133.

Alzheimer's New Zealand (2003): Alzheimer's: Book One. Alzheimer's Society. Auckland, New Zealand.

Brunton, M., Jordan, C., Fouche, C. (2008): Managing public health care policy: who's being forgotten ? Health Policy $88,348-358$.

Burns, A., lliffe, S. (2009): Dementia. Br. Med. J. 338:b75. doi: 10.1136/bmj.b75.

Dang, S., Badiye, A., Kelkar, G. (2008): The dementia caregiver - a primary care approach. South Med. J. 101, 1246-1251.

Ferri, C.P., Prince, M., Brayne, C., Brodaty, H., Fratiglioni, L., Ganguli, M., Hall, K., Hasegawa, K., Hendrie, H., Huang, Y., Jorm, A., Mathers, C., Menezes, P.R., Rimmer, E., Scazufca, M. (2005): Global prevalence of dementia: a Delphi Consensus study. Lancet 366, 2112-2117.

Folstein, M.F., Folstein, S.E., McHugh, P.R. (1975): "Mini Mental State": A practical method for grading the cognitive state of patients for the clinician. J. Psychiatr. Res. 12, 189198.

Katz, S., Ford, A.B., Moskowitz, R.W., Jackson, B.A., Jaffe, M.W. (1963): Studies of illness in the aged. The index of ADL: a standardized measure of biological and psychosocial function. J. Am. Med. Assoc. 185, 914-919.

Lawton, M.P., Brody, E.M. (1969): Assessment of older people: self-maintaining and instrumental activities of daily living. Gerontologist 9, 179-186.

Martin, R., Griffith, H.R., Belue, K., Harrell, L., Zamrini, E., Anderson, B., Bartolucci, A., Marson, D. (2008): Declining financial capacity in patients with mild Alzheimer disease: A one-year longitudinal study. Am. J. Geriatr. Psychiatry 16, 209-219.

Nguyen, V.T., Love, A.R., Kunik, M.E. (2008): Preventing aggression in persons with dementia. Geriatrics 63, 21-26.

Ory, M.G., Hoffman, R.R.3 ${ }^{\text {rd }}$, Yee, J.L., Tennstedt, S., Schulz, R. (1999): Prevalence and impact of caregiving: a detailed comparison between dementia and non dementia caregivers. Gerontologist 39, 177-185.

Pugliatti, M., Sobocki, P., Beghi E., Pini, S., Cassano, G.B., Altamura, A.C., Pozzoli, S., Rosati, G., Cost of Disorders of the Brain in Europe Study Group (2008): Cost of disorders of the brain in Italy. Neurol. Sci. 29, 99-107.

Shaw, W.S., Patterson, T.L., Semple, S.J., Dimsdale, J.E., Ziegler, M.G., Grant, I. (2003): Emotional expressiveness, hostility and blood pressure in a longitudinal cohort of Alzheimer caregivers. J. Psychosom. Res. 54, 293-302. 